\title{
Spectral discrimination of live prostate and bladder cancer cell lines using Raman optical tweezers
}

Tim J. Harvey

Elsa Correia Faria

Alex Henderson

University of Manchester

School of Chemical Engineering and Analytical Science

Manchester Interdisciplinary Biocentre

131 Princess Street

Manchester, Manchester M1 7DN

United Kingdom

\section{Ehsan Gazi}

University of Manchester

Christie Hospital NHS Trust

Paterson Institute for Cancer Research

Genito-Urinary Cancer Research Group

Withington, Manchester M20 4BX

United Kingdom

\section{Andrew D. Ward}

Science and Technology Facilities Council

Rutherford Appleton Laboratory

Central Laser Facility

Didcot, Oxfordshire OX11 OPX

United Kingdom

\section{Noel W. Clarke}

Michael D. Brown

University of Manchester

Christie Hospital NHS Trust

Paterson Institute for Cancer Research

Genito-Urinary Cancer Research Group

Withington, Manchester M20 4BX

United Kingdom

\section{Richard D. Snook}

\section{Peter Gardner}

University of Manchester

School of Chemical Engineering and Analytical Science

Manchester Interdisciplinary Biocentre

131 Princess Street

Manchester, Manchester M1 7DN

United Kingdom

\begin{abstract}
An investigation into the use of Raman optical tweezers to study urological cell lines is reported, with the ultimate aim of determining the presence of malignant $\mathrm{CaP}$ cells in urine and peripheral fluids. To this end, we trapped and analyzed live CaP cells (PC-3) and bladder cells (MGH-U1), because both prostate and bladder cells are likely to be present in urine. The laser excitation wavelength of $514.5 \mathrm{~nm}$ was used, with Raman light collected both in back- and forward-scattering geometric configurations. For the backscattering configuration the same laser was used for trapping and excitation, while for forward scattering a $1064 \mathrm{~nm}$ laser provided the trapping beam. Analysis of cell-diameter distributions for cells analyzed suggested normal distribution of cell sizes, indicating an unbiased cellselection criterion. Principal components analysis afforded discrimination of MGH-U1 and PC-3 spectra collected in either configuration, demonstrating that it is possible to trap, analyze, and differentiate PC-3 from MGH-U1 cells using a $514.5 \mathrm{~nm}$ laser. By loading plot analysis, possible biomolecules responsible for discrimination in both configurations were determined. Finally, the effect of cell size on discrimination was investigated, with results indicating that separation is based predominantly on cell type rather than cell size. ๑ 2008 Society of Photo-Optical Instrumentation Engineers. [DOI: 10.1117/1.2999609]
\end{abstract}

Keywords: Raman optical tweezers; vibrational spectroscopy; prostate cancer; cell lines; principal component analysis; chemometrics.

Paper 07488RR received Dec. 14, 2007; revised manuscript received Aug. 1, 2008; accepted for publication Aug. 23, 2008; published online Nov. 5, 2008.

\section{Introduction}

Prostate cancer $(\mathrm{CaP})$ is the most commonly diagnosed cancer in men. ${ }^{1}$ About 32,000 cases of prostate cancer are diagnosed in the UK every year, which accounts for $23 \%$ of all male cancers. The mortality rate for $\mathrm{CaP}$ is second only to lung cancer, with 10,000 deaths in the UK every year. The median

Address all correspondence to: Peter Gardner, University of Manchester, School of Chemical Engineering and Analytical Science, Manchester Interdisciplinary Biocenter, 131 Princess Street, Manchester, Manchester M1 7DN, United Kingdom; Tel: 0161-306-4463; Fax: 0161-306-5201; E-mail: peter.gardner@ manchester.ac.uk. life expectancy for patients suffering from secondary prostate cancer in the bone is about 18 months. $^{2}$

Current preoperative methods of detection include digital rectal examination (DRE) and the prostate-specific antigen (PSA) test. ${ }^{3,4}$ The PSA method measures the concentration of PSA (a glycoprotein) in the blood serum, but the threshold for a positive test is uncertain and a significant number of men have cancer in the presence of a low PSA. ${ }^{5}$ While both the PSA and DRE methods are sensitive to the presence of cancer, they suffer from low specificities, resulting in a high falsepositive rate and unnecessary biopsies. Results have shown

1083-3668/2008/13(6)/064004/12/\$25.00 @ 2008 SPIE 
that for patients with a positive PSA test, only $22 \%$ have a definitive cancer diagnosis following biopsy. ${ }^{6}$ What the clinician requires is a noninvasive diagnostic tool that is both sensitive and specific. This will facilitate accurate diagnosis and reduce the rate of unnecessary biopsies.

An analysis method that could potentially enhance current diagnostic methods involves the detection and analysis of prostate cells in urine or peripheral fluids such as blood. While it is known that massaging of the prostate gland results in shedding of cells into the urine, ${ }^{7,8}$ cancer cells are also present in the peripheral fluids such as blood or lymph., ${ }^{9,10}$

Noninvasive, in vitro Fourier transform infrared spectroscopy (FTIR) and Raman spectroscopy are powerful bioanalytical tools for the identification, classification, and diagnosis of cancer cells or tissue. ${ }^{11-14}$ The transition of a normal cell to its diseased state is accompanied by changes in a variety of biomolecules, which can be simultaneously and indiscriminately probed by FTIR and Raman spectroscopy. This yields spectral signatures which enable differentiation between normal and cancerous cells and tissues. ${ }^{13,15}$

The changes in cell biochemistry that can occur during transition of a normal cell to a malignant cell have been studied extensively using FTIR. Examples of such changes include the increase in nucleic acid contributions, ${ }^{16,17}$ frequency shift in phosphate bands, ${ }^{18}$ and reduction in the glycogen-tophosphate ratios. ${ }^{19,20}$

Research has shown that it is possible not only to distinguish between cancerous and noncancerous prostate epithelial tissues by use of FTIR but also to correlate FTIR spectra with the Gleason grade ${ }^{19,21}$ (the histopathological gold standard for grading malignant prostate tissue following biopsy ${ }^{22}$ ). Different metastatic $\mathrm{CaP}$ cell lines have also been distinguished based on their spectra by use of FTIR-photoacoustic spectroscopy ${ }^{23}$ and Raman microspectroscopy. ${ }^{24}$

In this paper, the use of a combined optical tweezers and Raman spectroscopy technique (Raman tweezers) to record spectra of single prostate cancer cells in the optical trap is reported. Validated Raman tweezer technology of this type offers the potential for single-cell analysis in urine and peripheral fluids. However, because other epithelial cells are present in urine, bladder cancer cells are also included in the study. The aim was to determine whether Raman spectra of these cell lines could be distinguished using chemometrics as a precursor to the development of a diagnostic technique. The $\mathrm{CaP}$ studied was the PC-3 cell, a bone marrow metastatic cell line ${ }^{25}$ while the bladder cancerous cell was represented by the MGH-U1 cell line. ${ }^{26}$ A smaller study was also carried out using LNCaP cells, which is a lymph node metastatic $\mathrm{CaP}$ cell line. $^{27}$

The principle of optical traps and optical tweezers was developed by Ashkin, ${ }^{28}$ who used this technique to trap and manipulate micro-organisms. ${ }^{29-31}$ An optical trap is created when a laser beam is brought to a tight focus by use of a high numerical aperture (NA) objective. An optical force, which is due to the transfer of momentum from the scattering of incident photons, impinges on the particle at the focal point. This force has two components: scattering, which is in the direction of light propagation, and gradient force, which is in the direction of spatial light gradient. For a stable optical trap, the gradient force pulling the particle toward the focal point must be greater than the scattering component of the force pushing the particle in the opposite direction. ${ }^{32}$

Combining Raman spectroscopy with optical tweezers (Raman tweezers) allows the spectroscopic analysis of micrometer-size particles and biological cells. Thus, Raman tweezer technology has been applied to study micro-organisms, ${ }^{33-37}$ blood cells, ${ }^{38-41}$ and, to a lesser extent, malignant cells ${ }^{42-44}$ Trapping of cells also allows levitation of the cells above the substrate, thus reducing fluorescence effects as well as Brownian motion from untrapped cells. In this study, two different experimental configurations were studied, forward-scattering Raman collection and backscattering Raman collection. In backscattering mode the same laser was used for trapping and probing (single beam), while for forward scattering two different beams were used for these two activities (dual beam). Figure 1 shows simplified schematics of both configurations. The rationale for the forwardscattering geometry is that the probe beam can be focused using a lower NA optical arrangement to produce a larger beam waist that matches that of a typical prostate epithelial cell $(\sim 20 \mu \mathrm{m}$ diam), therefore allowing the majority or the whole of the cell to be probed. In contrast the proportion of the cell probed in the backscattering configuration may be limited, because the beam waist that the cell is trapped in is highly focused, thus restricting the Raman excitation volume. Calculations suggest that, using the optics discussed in the following text, about $45 \%$ of the cell is probed using the backscattering configuration. However, unlike for forward scattering, the cell is not homogenously probed, as the intensity of the beam, and thus the intensity of Raman light generated, diminishes as the beam diverges away from the focal point.

\section{Methods and Materials}

\subsection{Raman Tweezer Configuration Setups}

Figures 2(a) and 2(b) show diagrams of the optical arrangements for backscatter and forward-scatter configurations, respectively.

\subsubsection{Backscattering configuration setup}

Laser light at $514.5 \mathrm{~nm}$ was delivered from a continuouswave argon ion laser (Innova 90-5-UV) through two telescope arrangement of lenses. The telescopes allowed for slight expansion of the beam, and overfilling of the objective, with improved trapping efficiencies. ${ }^{32}$ Laser light then passed through an edge filter and directed to the inverted microscope (Leica DM IRB) via a dichroic mirror and an objective lens (Leica, 1.2 NA, water immersion). Backscattered light from a trapped cell was collected through the objective directed to a Princeton Instrument Spec 10:400 nitrogen-cooled charged coupled detector (CCD) via a 1200 groove/mm grating blazed at $600 \mathrm{~nm}$. An edge filter to remove the Rayleigh line from Raman signal was placed between the microscope and detector. Raman light was focused onto the spectrograph by means of an f6 lens.

\subsubsection{Forward-scattering configuration setup}

$1064 \mathrm{~nm}$ laser light for cell trapping was delivered from a $\mathrm{Nd}$ :yttrium aluminum garnet (YAG) laser to the microscope 


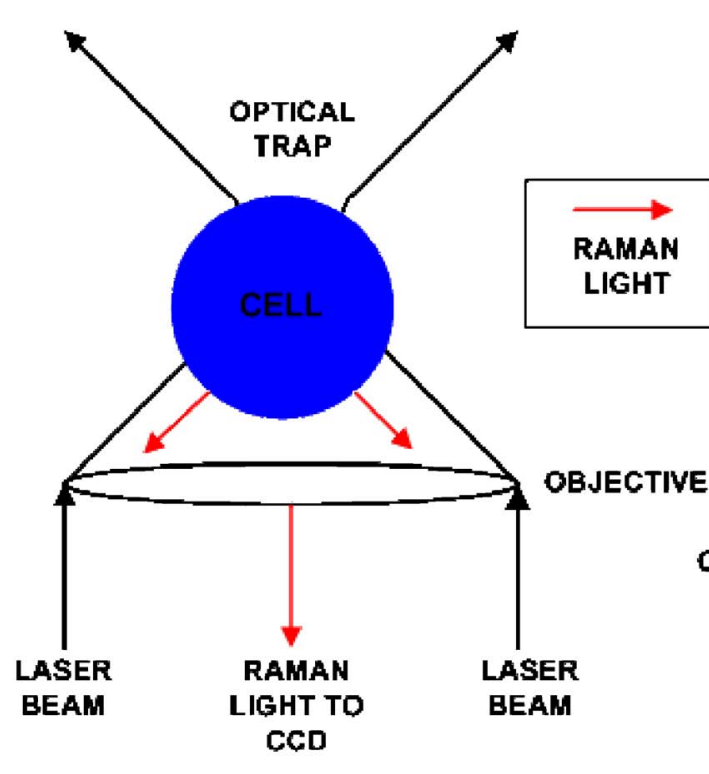

(a)

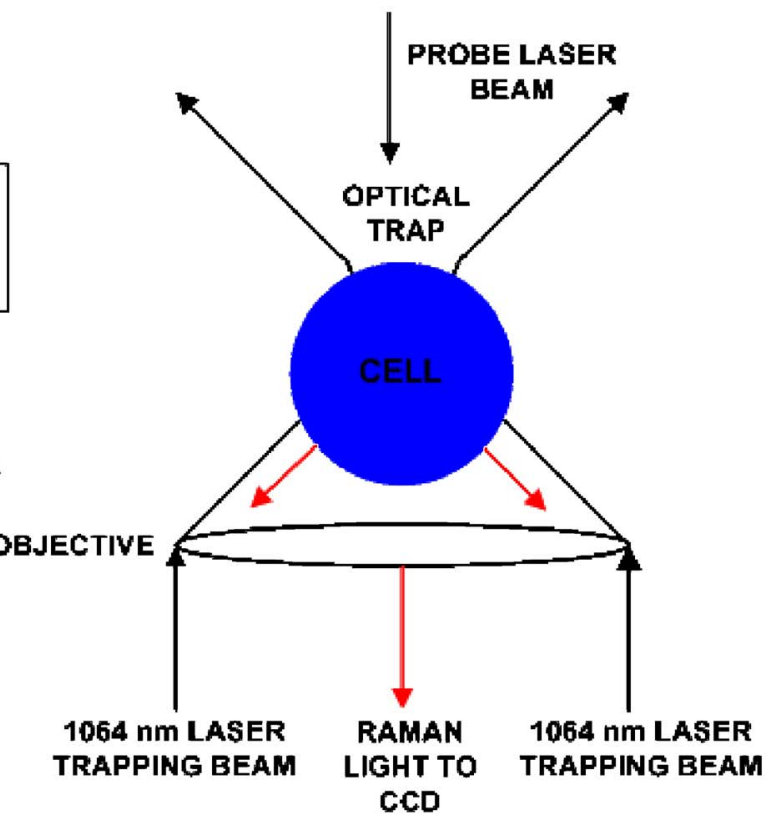

(b)

Fig. 1 Raman tweezer configurations; (a) single-beam backscatter and (b) dual-beam forward scatter.

stage via the objective lens. A similar arrangement of telescope lenses to that used for the backscattering configuration was used. A Raman differentiator, located after the second telescope, enabled the passing of probe laser light but reflection of Raman scattered light. Simultaneously, the trapped cell was probed from above the sample by a $514.5 \mathrm{~nm}$ argon ion laser, with a laser waist of approximately $20 \mu \mathrm{m}$. Laser light was focused onto the sample by means of a condenser. Scattered light was forward scattered, collected with the objective lens, reflected by the Raman differentiator, and directed to the CCD via an edge filter, a f6 lens, and a 1200 groove/ $\mathrm{mm}$ grating blazed at $600 \mathrm{~nm}$.

\subsection{Cell Preparation}

Both PC-3 and MGH-U1 cells were cultured in Ham's F12, $7 \%$ fetal calf serum (FCS), and $2 \mathrm{mM}$ L-glutamine. LNCaP cells were cultured in RPMI 1640, 10\% FCS, and $2 \mathrm{mM}$ L-glutamine. All cultures were grown in T25 flasks at $37^{\circ} \mathrm{C}$ in a humidified atmosphere of $5 \% \mathrm{CO}_{2}$ in air. Once the cells reached $70 \%$ confluence, they were displaced from the flask by addition of $1 \mathrm{~mL}$ of trypsin. This was followed by addition of $5 \mathrm{~mL}$ of the growth media. If required, a portion of these cells was used for further subcultures, while the rest were used for experiments. The cells used for experiments were dispensed into $1 \mathrm{~mL}$ aliquots (equivalent to $1 / 6$ of a T25 flask) to falcon tubes and stored on ice until required for analysis. The $1 \mathrm{~mL}$ aliquots containing cells in growth media were centrifuged at $1500 \mathrm{rpm}$ for $5 \mathrm{~min}$. The growth media was then decanted off, leaving a cell pellet at the bottom of the falcon tube. $1 \mathrm{~mL}$ of phosphate-buffered saline solution (PBS) was added to the pellet and aspirated to ensure the cells were fully suspended in the PBS. All tissue-culture media were obtained from Invitrogen, Paisley, UK, and all other reagents were purchased from Sigma-Aldrich, Poole, UK.

\subsection{Cell Trapping and Raman Collection}

The trapping and Raman collection methods varied slightly depending on configuration used.

\subsubsection{Backscattering configuration}

A quartz dish containing approximately 200-300 $\mu \mathrm{m}$ of PBS/cells was placed on the microscope stage. Cells were trapped by moving the stage in a horizontal $x-y$ direction, so that a cell was positioned within the center of the trap. If required, the focus ( $z$ direction) was changed to trap the cell. Once trapped, the focus was altered to levitate the cell above the substrate (height not quantified), and a Raman spectrum was subsequently collected. The cell was released from its trap, and a spectrum of the PBS background was recorded without changing the focus. This procedure was repeated for a number of different cells. Spectra for each cell were collected over a $30 \mathrm{~s}$ time period, with a laser output power of $350 \mathrm{~mW}$. This resulted in a power of $27.5 \mathrm{~mW}$ delivered to the cell as measured by a power meter placed at the sample position on the microscope stage.

\subsubsection{Forward-scattering configuration}

The trapping procedure for this configuration was effectively the same as for the backscattering configurations. For Raman collection the probe beam was positioned so that the center of the focus point was over the center of the cell. Spectra for each cell were then collected over a $30 \mathrm{~s}$ time period, with a laser output power of $350 \mathrm{~mW}$, which was measured to be $63.9 \mathrm{~mW}$ at the sample. The trapping $1064 \mathrm{~nm}$ beam was operating at $370 \mathrm{~mW}$, which was measured to be $27.5 \mathrm{~mW}$ at the sample. 


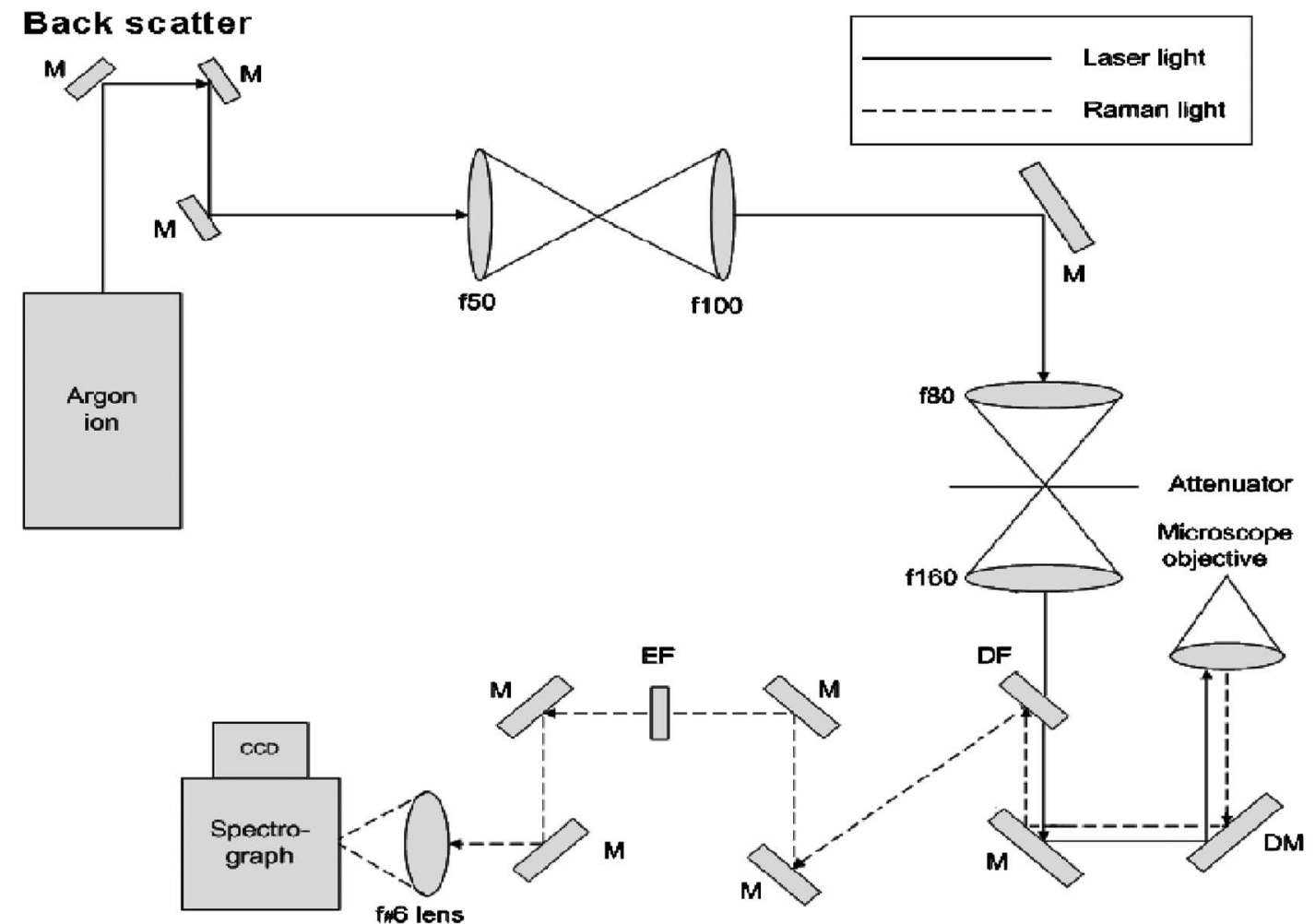

(a)

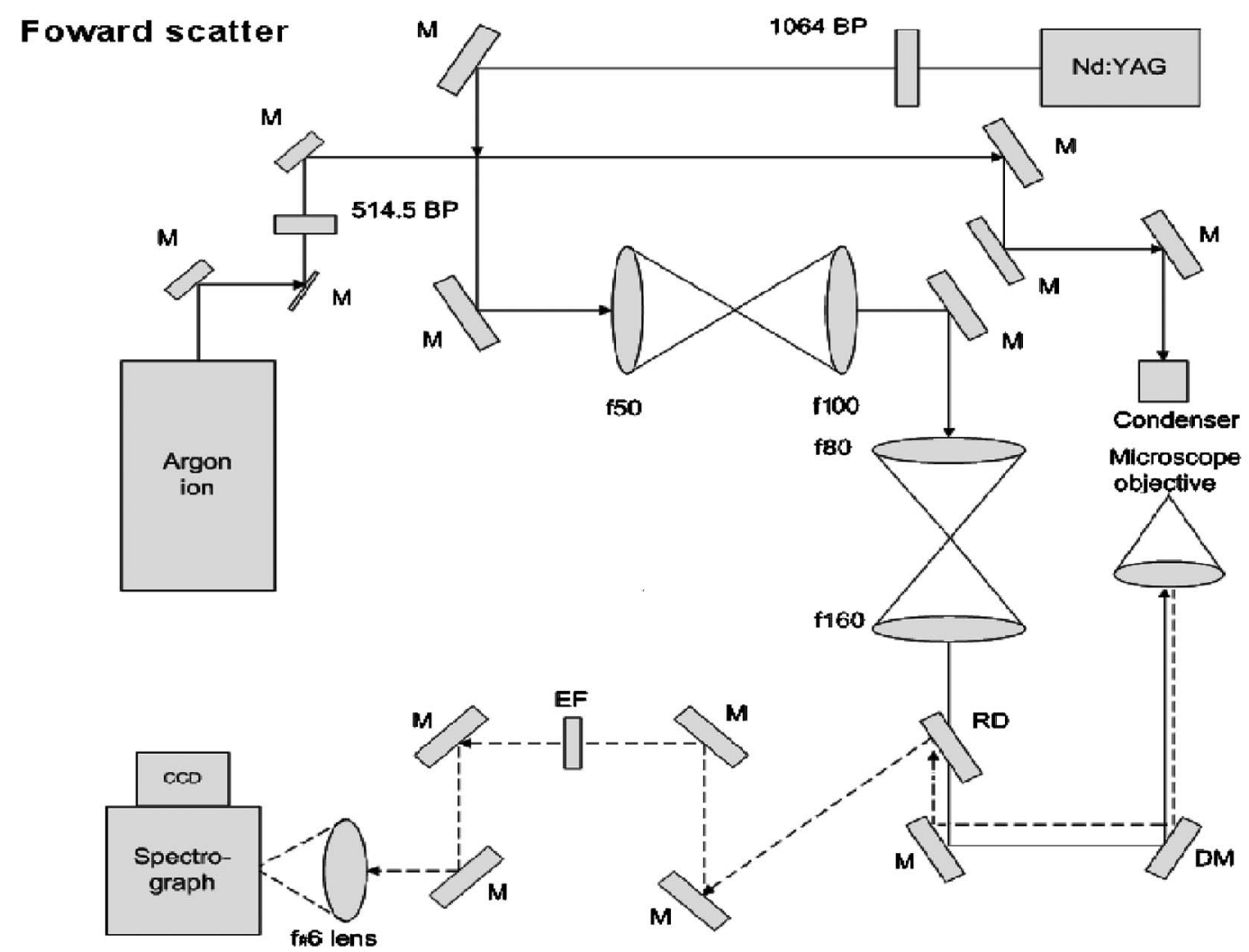

(b)

Fig. 2 Diagrams of the Raman tweezer configuration setups for (a) backscatter and (b) forward-scatter configurations. Key to abbreviations: M, mirror; EF, edge filter; BP, bandpass filter; BS, beam splitter; DM, dichroic mirror; DF, dichroic filter; RD, Raman differentiator; CCD, chargecoupled detector. 


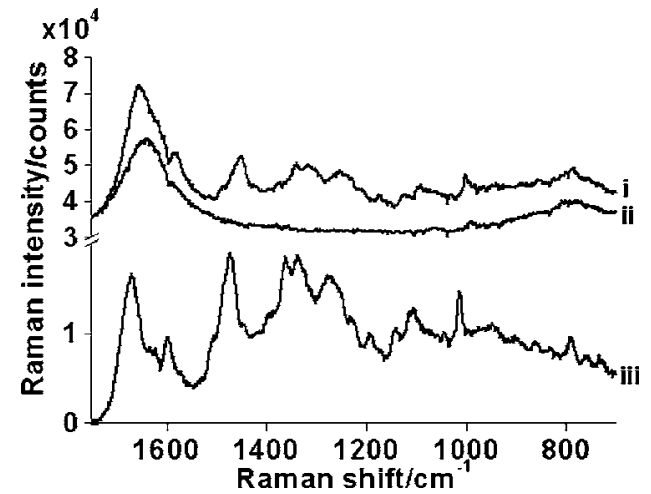

Fig. 3 Raman spectra of (i) bladder (MGH-U1) cell in PBS (raw spectrum), (ii) background spectrum of PBS, and (iii) background subtracted spectrum of bladder (MGH-U1) cell.

\subsection{Data Processing}

Following spectral acquisition, each spectrum was converted into ASCII files and transported into OMNIC software. The background was subtracted from each raw spectrum to obtain the actual cell spectrum (see Section 2.3.1 for backgroundcollection procedure). A similar background-subtraction procedure was used by Chen et al. ${ }^{43}$ and Hamden et al. ${ }^{44}$ The spectral region $700-1750 \mathrm{~cm}^{-1}$ was used for analysis. Spectra were initially subjected to extended multiplicative scattering correction (EMSC), followed by vector normalization and mean centering. Vector normalization, mean centering, and principal components analysis (PCA) were carried out using Matlab (Mathworks, Inc) using built-in algorithms. EMSC was carried out using Unscrammbler (Camo Inc) software. All other statistical analysis was carried out using SPSS Release 11.0.0 (SPSS, Inc).

\section{$2.5 E M S C$}

The EMSC method was developed by Martens and Stark to correct for additive (baseline) and multiplicative effects in near-infrared spectroscopy. ${ }^{45}$ The superimposition of baselines on Raman spectra results in baseline shift, which requires removal as a preprocessing step. Recently, EMSC has found applications in correcting Raman spectra of biological samples. ${ }^{46-49}$

EMSC was developed from an earlier method, the multiplicative signal correction (MSC) method. In the MSC method, the additive and multiplicative effects are first estimated by least-squares regression with respect to a reference spectrum. The corrected spectrum is then obtained by subtracting every original value by the additive effect and dividing by the multiplicative effect. EMSC builds on MSC by correcting for wavelength-dependent spectral variations from sample to sample.

\section{Results and Discussion}

\subsection{Background Subtracted Spectrum}

Figure 3 shows $(i)$ a raw bladder (MGH-U1) spectrum, $(i i)$ the background spectrum of PBS, and (iii) the resulting background subtracted spectrum. The raw spectrum shows an increase in intensity with decreasing wavenumber, which was not observed in the background spectrum and which is most probably caused by fluorescence. This results in a slight slope in the baseline of the background subtracted spectrum.

\subsection{Cell-Size Distribution}

Histograms for MGH-U1 and PC-3 cell diameters are shown in Fig. 4(a) and 4(b). Optical images of a typical MGH-U1 and PC-3 are displayed in Fig. 4(c) and 4(d). The data show that PC-3 cells are larger than MGH-U1 with a mean diameter of $26.9 \mu \mathrm{m}( \pm 4.7 \mu \mathrm{m})$ compared with $19.1 \mu \mathrm{m}$
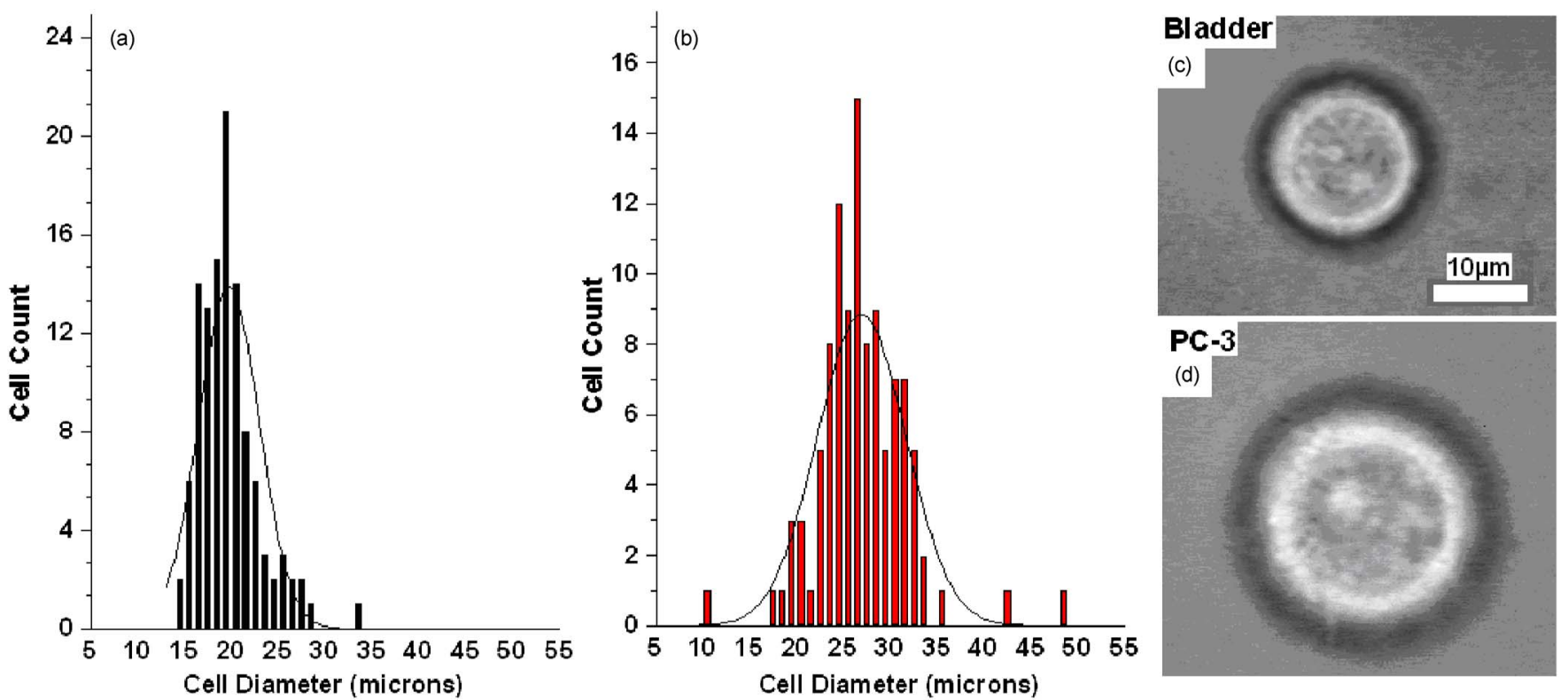

Fig. 4 Histograms showing distribution of cell diameter for (a) bladder (MGH-U1) and (b) PC-3. The normal distribution curve is also included. (c) Optical image of a typical trapped bladder and (d) PC-3 cell. 


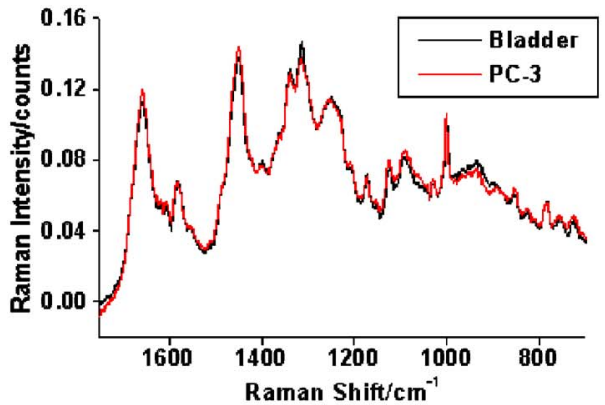

(a)

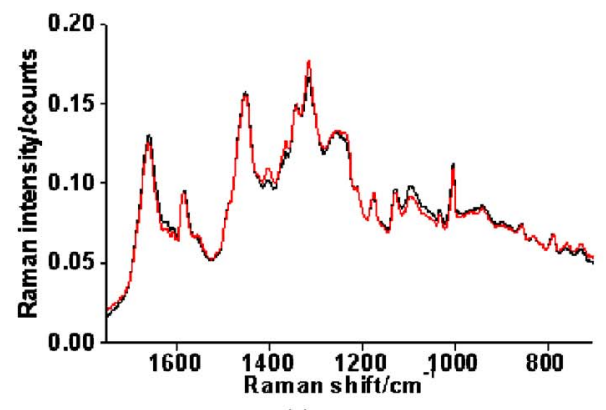

(c)

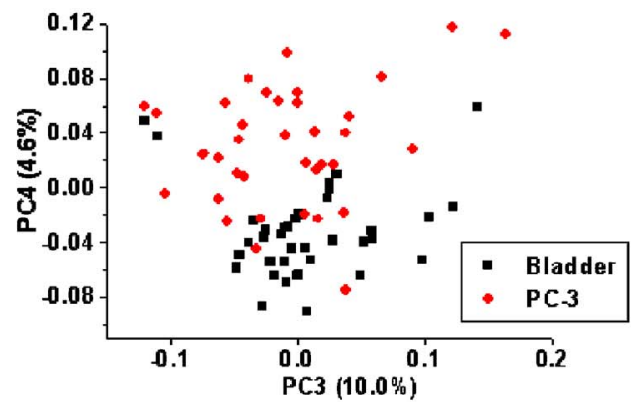

(b)

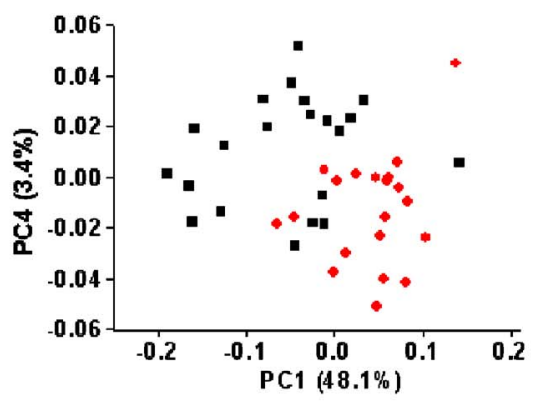

(d)

Fig. 5 (a) Mean vector-normalized spectra and (b) PCA plot from backscatter configuration. (c) Mean spectra and (d) PCA plot from forward-scatter configuration. Each point in the PCA plot represents one spectrum.

$( \pm 3.1 \mu \mathrm{m})$. A one-way ANOVA test shows that these means are not equal at $95 \%$ confidence level. Superimposed on each histogram is a normal distribution curve. Visual examination of the histograms and normal distribution curves suggests that PC-3 and MGH-U1 cells are normally distributed. However, the MGH-U1 histogram shows a slight skew of the distribution, with the low diameter end less normally distributed as observed with Chinese hamster ovary cells. ${ }^{49}$ This observation is confirmed by the Kolmogrov-Smirnov (K-S) test, which tests for the probability that a collection of data is normally distributed. At a confidence level of $95 \%$, the K-S test shows that the PC-3 cells are normally distributed but MGH-U1 are not. However, when the confidence level is increased to $98 \%$, both cell types are normally distributed. The fact that bladder cells are smaller than PC-3 cells and that there is probably a minimum size of a cell that could exist might skew the MGH-U1 distribution at the low-diameter end. This could explain why PC-3 cells are more normally distributed than MGH-U1 cells. However, the results show that the cells were randomly selected for analysis without introducing any intentional or unintentional bias into the selection criteria. This is important because there was a concern that the small cells may trap preferentially to the larger ones, particularly the very large prostate cells, but the data show that this is not the case.

\subsection{Raman Spectra and PCA Plots}

Figure 5(a) shows the vector-normalized mean spectra for prostate and bladder cells taken using the backscattering configuration, with the resulting PCA plot shown in Fig. 5(b). The spectra represent the mean of 39 and $38 \mathrm{MGH}-\mathrm{U} 1$ and PC-3 spectra, respectively. The data in this PCA plot were obtained from two different cell cultures, i.e., two independent replicates for each cell line, and analyzed over two different days.
No subclusters within each cell line are obvious in the PCA plot, which suggests that biological differences within a cell line are small compared with differences between cell lines and that cell culturing procedures are reproducible.

Figure 5(c) shows the vector-normalized mean spectra taken in the forward-scattering configuration, with the resulting PCA plot shown in Fig. 5(d). The spectra represent the mean of 22 and 20 bladder and PC-3 spectra, respectively. In the PCA plot, each data point represents a single spectrum.

Mean standard deviations/(normalized counts) for both configurations were calculated over the wavenumber range $700-1750 \mathrm{~cm}^{-1}$. For backscattering, this gave values of 0.015 and 0.032 for MGH-U1 and PC-3, respectively. For forward scattering, values of 0.023 and 0.010 for MGH-U1 and $\mathrm{PC}-3$, respectively, were obtained.

The PCA plots show separation of the PC-3 and MGH-U1 cells for both configurations. Although the separation is not $100 \%$ in each case, the data suggests that PC-3 and MGH-U1 cells can be discriminated based on their respective spectra. Separation occurs mainly on the PC4 axis in each case, accounting for 4.6 and $3.4 \%$ of the total variance, respectively.

\subsection{Factor-Loading Plot Analysis}

To determine which biochemical features were responsible for the discrimination seen in Fig. 5(a) and 5(b), the loadings for the principal components ( $\mathrm{PC} 4$ in each case) that separated the cells in each PCA plot were plotted together (Fig. 6). For the backscattered plot, the majority of PC-3 spectra have positive scores on PC4, while for the forward-scattered plot the majority of bladder spectra have positive scores on PC4. Observation of both plots together shows that many spectral features are anticorrelated to each other (i.e., have a negative loading in one plot but positive loading in the other). Bio- 


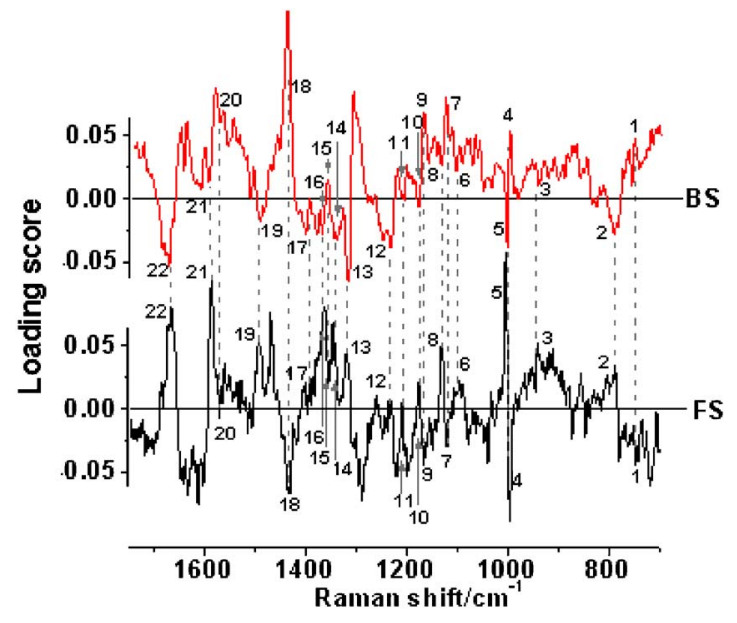

Fig. 6 Loading plots for forward-scatter (FS) and backscatter (BS) configurations. Vertical dashed gray lines link pairs of anticorrelated peaks. Numbers for each pair of anticorrelated peaks relate to band assignments given in Table 1.

chemical moieties assigned to these features are likely to be responsible for discrimination in both configurations.

Spectral features relating to positive peaks for the forwardscattering configuration loading plot are more intense in MGH-U1 cells than PC-3, because MGH-U1 is highly correlated to PC4. Because spectral intensity is related to concentration, biochemical moieties assigned to these features may be present in relatively greater amounts in MGH-U1 cells than PC-3 cells. However, spectral features relating to negative peaks in the backscattering configuration loading plot are less intense in PC-3 than MGH-U1, because PC-3 is highly correlated to PC4. Therefore, biochemical moieties assigned to these features are likely to be present in relatively smaller amounts in PC-3 cells than MGH-U1 cells.

Table 1 shows positions of peaks in the factor-loading plots, with tentative assignments for moieties that are likely to be responsible for discrimination in both configurations. The Raman band assignments were obtained from Ref. 35, 44, and 50-56. The table shows a consistent assignment of Raman bands in the loading plot. This is highlighted by the fact that protein and nucleic acid moieties mainly have positive loadings for the forward-scattering configuration, while all lipid and carbohydrate moieties have positive loadings for the backscattering configuration. For example, bands assigned to spectrum peaks $15,17,18$, and 20 are lipid moieties, and all have positive loadings for backscattering configuration. Spectrum peaks 12,13 , and 14 are assigned to nucleic acid and proteins, and these have positive loadings for the forwardscattering configuration.

From these assignments, proteins and nucleic acids can be considered to be more abundant in MGH-U1 than PC-3 cells, while lipids and carbohydrates are more abundant in PC-3 cells. Nucleic acids and proteins are mainly found in the cell nucleus, while lipids are largely distributed within the cytoplasm and cell membrane. Therefore, differences in these biochemical amounts between PC-3 and MGH-U1 may be a consequence of differences in the nucleus-to-cytoplasm ratio between these cells. It is possible that this could be linked to cell size, as the proportion of nucleus and cytoplasm probed is likely to vary with cell size. The role of the nucleus-tocytoplasm ratio in the spectral discrimination of cell types was investigated by Romeo et al. ${ }^{57}$ Determining if this postulation holds, by measuring the relative nucleus area to cytoplasm area in both cell types, is beyond the scope of this work, because the nucleus could not be clearly differentiated in the cell images obtained during data acquisition.

\subsection{Effect of Cell Size on PCA Separation}

From the histograms in Fig. 2(a) and 2(b), it was shown that PC-3 cells are generally larger than MGH-U1 cells. Therefore, PCA separation of the PC-3 from MGH-U1 cells may be due to cell size. It is also possible that discrimination may be due to differences in cell biochemistry but as an indirect consequence of the cell size. This is because a small cell has a relatively large surface area to total cell volume compared with a larger cell. Therefore, a smaller cell may contain more membrane biomolecules (membrane lipids and proteins) relative to nonmembrane biomolecules compared with a larger cell. ${ }^{58,59}$ Thus, it could be possible to explain discrimination of PC-3 from MGH-U1 on the basis of both cell biochemistry and cell size.

To examine the effect of cell size on discrimination, scatter plots of PC score versus cell size (diameter) were generated [Fig. 7(a) and 7(b)]. PC4 score was chosen, because most of the separation occurs on this component [see Fig. 5(b) and 5(d)]. Observation of Fig. 7(a) (backscatter) shows a tentative relationship between cell size and PC4 score, with the score increasing with increasing cell diameter. The majority of MGH-U1 cells have a negative score and are generally smaller than the PC-3 cells, which generally have a positive score. For the forward-scattering plot [Fig. 7(b)], a relationship between score and size is even more tenuous. The bladder cells distributed significantly more on the score axis than on the cell-size axis. For PC-3 cells they are distributed more on the cell-size axis than score axis. This would suggest that there is little or no relationship between score and cell size.

From these plots, no firm conclusions can be made on whether cell discrimination is due to cell size. To further this investigation, we obtained 10 Raman spectra of $\mathrm{LNCaP}$ cells using the forward-scattering configuration (parameters and data processing were the same as for the other cells). The mean diameter of these cells was $19.8 \mu \mathrm{m}$ ( \pm 1 standard deviation), and they were therefore closer in size to MGH-U1 than PC-3 cells. The spectra obtained for the LNCaP cells were added to those from the PC-3 and MGH-U1 cells, and the whole data set was reanalyzed as described in Section 2.4.

The resulting PCA plot incorporating LNCaP cells is shown in Fig. 8(a), and a scatter plot of PC4 score versus cell size for LNCaP, MGH-U1, and PC3 cells is shown in Fig. 8(b). Note that each time new data is added to the PCA, the resulting PCs may change. Thus, this new PC4 is not necessarily the same as the one in Fig. 5(d) and may correspond to different biochemical features.

Figure 8(a) shows that the majority of $\mathrm{LNCaP}$ cells are separated well away from MGH-U1 and PC-3, with the latter two cell types clustering close together. This result suggests that cells of similar size can be discriminated, as LNCaP cells do not cluster close to MGH-U1 cells. The lack of a relationship between discrimination and cell size is also tenuously 
Table 1 Assignment of loadings for both back- and forward-scattering configurations. The spectrum ID number for each pair of bands relates to the numbers in Fig. 6 . Key to abbreviations: A, adenine; $\mathrm{C}$, cytosine; G, guanine; T, thymine; $U$, uracil; Phe, phenylalanine; Trp, tryptophan; Tyr, tyrosine.

\begin{tabular}{|c|c|c|c|c|c|}
\hline \multirow[b]{2}{*}{ Spectrum ID } & \multicolumn{2}{|c|}{$\begin{array}{l}\text { Forward-scatter } \\
\text { loading }\left(\mathrm{cm}^{-1}\right)\end{array}$} & \multicolumn{2}{|c|}{$\begin{array}{l}\text { Backscatter } \\
\text { loading }\left(\mathrm{cm}^{-1}\right)\end{array}$} & \multirow[b]{2}{*}{ Tentative assignments } \\
\hline & $+\mathrm{ve}$ & $-v e$ & $+\mathrm{ve}$ & $-v e$ & \\
\hline 1 & & 745 & 749 & & $\begin{array}{l}\text { T (ring breathing of DNA/RNA) } \\
\text { Possibly also } \mathrm{CH}_{2} \text { bend (lipids) }\end{array}$ \\
\hline 2 & 792 & & & 789 & $\begin{array}{l}\mathrm{C}, \mathrm{T}, \mathrm{U}, \mathrm{PO}_{2}^{-} \text {symmetric stretch, } \\
\text { phosphodiester band (nucleic acids) }\end{array}$ \\
\hline 3 & 941 & & & 942 & C-C stretch $\alpha$-helix (proteins) \\
\hline 4 & & 998 & 994 & & $\begin{array}{l}\mathrm{C}-\mathrm{C}, \mathrm{C}-\mathrm{O} \text { ribose } \\
\text { Stretch and bend ring of uracyl }\end{array}$ \\
\hline 5 & 1002 & & & 1002 & $\begin{array}{l}\text { Phe ring breathing, } \mathrm{C}-\mathrm{C} \text { aromatic } \\
\text { ring stretching (proteins) }\end{array}$ \\
\hline 6 & 1098 & & & 1102 & $\mathrm{PO}_{2}^{-}$symmetric stretch \\
\hline 7 & & 1120 & 1124 & & $\begin{array}{l}\mathrm{C}-\mathrm{C} \text { stretch (lipids), } \mathrm{C}-\mathrm{O}-\mathrm{C} \\
\text { symmetric stretch (carbohydrates) }\end{array}$ \\
\hline 8 & 1131 & & & 1133 & $\begin{array}{l}\text { C-C stretch, } \mathrm{C}-\mathrm{C} \text { asymmetric stretch } \\
\text { (proteins) }\end{array}$ \\
\hline 9 & & 1165 & 1169 & & $\begin{array}{l}\mathrm{C}-\mathrm{O} \text { stretch, } \mathrm{C}-\mathrm{OH} \text { bend (lipids) } \\
\mathrm{CO}_{2} \mathrm{C} \text { (carbohydrates) }\end{array}$ \\
\hline 10 & 1176 & & & 1179 & $\begin{array}{l}\mathrm{C}-\mathrm{O} \text { stretch, } \mathrm{C}-\mathrm{OH} \text { bend, (proteins), } \\
\mathrm{C}, \mathrm{G} \text { (nucleic acids) }\end{array}$ \\
\hline 11 & 1210 & & & 1210 & $\begin{array}{l}\mathrm{C}-\mathrm{C}_{6} \mathrm{H}_{5} \text { stretch mode in Phe and Tyr } \\
\text { (proteins) }\end{array}$ \\
\hline 12 & 1232 & & & 1232 & $\begin{array}{l}\mathrm{PO}_{2}^{-} \text {asymmetric stretch, } \mathrm{RNA}, \\
\mathrm{DNA} \text { (nucleic acids), Amide III } \\
\text { (proteins) }\end{array}$ \\
\hline 13 & 1319 & & & 1316 & $\begin{array}{l}\mathrm{G} \text { (nucleic acids), } \mathrm{CH} \text { def (proteins), } \\
\mathrm{CH}_{2} \text { twist and bend (nucleic } \\
\text { acids/proteins) }\end{array}$ \\
\hline 14 & 1347 & & & 1341 & $\begin{array}{l}\text { A, G (nucleic acids), Phe (proteins), } \\
\mathrm{CH} \text { def (proteins) }\end{array}$ \\
\hline 15 & & 1355 & 1360 & & $\mathrm{CH}_{3}$ symmetric stretch (lipids) \\
\hline 16 & 1361 & & & 1369 & $\begin{array}{l}\mathrm{CH}_{3} \text { symmetric bend (proteins), } \\
\mathrm{G} \text { (nucleic acids) }\end{array}$ \\
\hline 17 & & 1391 & 1396 & & $\mathrm{CH}_{3}$ bend, $\mathrm{CH}$ rocking (lipids) \\
\hline 18 & & 1438 & 1434 & & $\mathrm{CH}_{2}$ def (lipids) \\
\hline 19 & 1493 & & & 1487 & $G$ (nucleic acids) \\
\hline 20 & & 1568 & 1567 & & $\begin{array}{l}\mathrm{CO}_{2}^{-} \text {antisymmetric stretch (lipids), } \\
\text { Phe, Trp (proteins) }\end{array}$ \\
\hline 21 & 1592 & & & 1592 & Tyr/Trp (proteins) \\
\hline 22 & 1668 & & & 1671 & $\begin{array}{l}\text { Amide I; } \mathrm{C}=\mathrm{O} \text { stretching of amide } \\
\text { coupled to } \mathrm{NH}_{2} \text { in -plane bending } \\
\text { (proteins) }\end{array}$ \\
\hline
\end{tabular}




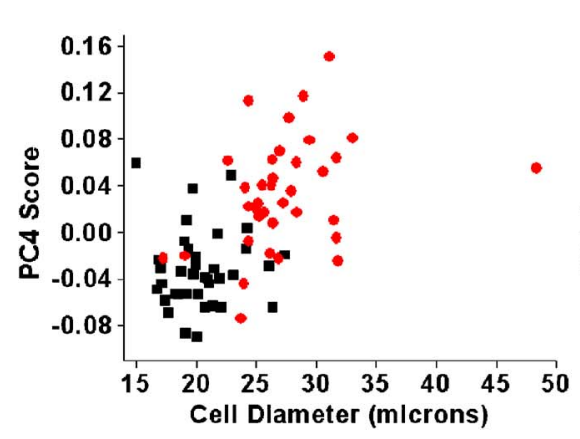

(a)

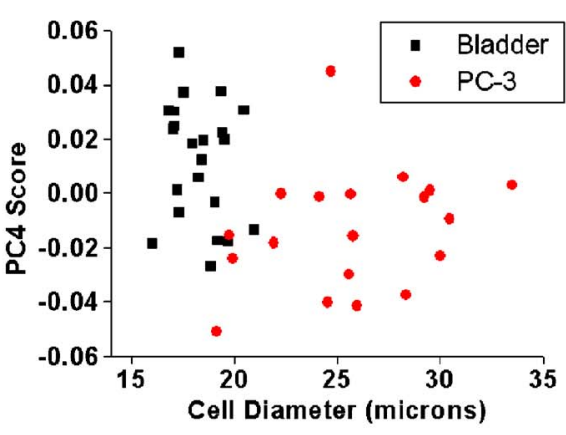

(b)

Fig. 7 Scatter graph showing correlation between cell size and PC4 score for (a) backscatter and (b) forward scatter.

confirmed by the scatter plot of the new PC4 score versus cell size [Fig. 8(b)], in which the majority of LNCaP cells, which are similar in size to MGH-U1 cells, are separated on the PC4 axis, suggesting cell size is not the dominant factor responsible for discrimination. However, the influence of cell size on the discrimination of cells has not been conclusively determined, as two LNCaP cells have clustered with MGH-U1. Thus, the influence of cell size on the separation of cells need to be investigated further by studying more cell lines.

\subsection{Consideration of Photoinduced Damage}

It is likely that the laser powers used for this study induce some degree of photodamage to the cell, principally, at these wavelengths, photo-oxidation. A study by Puppels et al. showed that damage to human lymphocytes occurs at the $514.5 \mathrm{~nm}$ wavelength for powers of $5 \mathrm{~mW},{ }^{60}$ and furthermore, Wood et al. showed that prolonged exposure at $632.8 \mathrm{~nm}$ using as little as $1 \mathrm{~mW}$ could induce changes in the spectra of human erythrocytes. ${ }^{61}$ It was therefore important to examine the impact of photoinduced damage on our results, even though our ultimate aim is to classify the cells and thus the fate of the cell is not necessarily important.

To study the influence of exposure, we trapped a PC-3 cell in backscattering configuration for an extended period of time, taking spectra every $30 \mathrm{~s}$. Every spectrum obtained for the first $3 \mathrm{~min}$, together with spectra obtained for 5, 10, 15, 20, and $25 \mathrm{~min}$ exposure time, was added to those from the PC-3 and MGH-U1 cells [same data as in Fig. 5(b)], and the whole data set was analyzed as described in Section 2.4. Fig- ure 9(a) shows the resulting PCA plot, with the additional time-course spectra highlighted in blue. This shows that all the additional PC-3 spectra have positive PC4 scores and have clustered with the PC-3 spectra (in red) obtained from the normal exposure time of $30 \mathrm{~s}$.

The region of the PCA plot in which the additional timecourse spectra are located is expanded, as shown in Fig. 9(b). Each data point is labeled with its respective exposure time (in minutes). This figure clearly shows a trend of increasing exposure time from left to right on the PC3 axis (increasing positive PC3 score with increasing time).Therefore, the PC3 axis could represent an increase in cell photodamage for these spectra.

However, the most important point of both Fig. 9(a) and 9(b) is that the separation between the spectrum obtained at $0.5 \mathrm{~min}$ (normal exposure) and spectra obtained at subsequent longer exposures is smaller than the separation between PC-3 (red) and MGH-U1 (black) spectra. This is most notable for spectra obtained during the first $3 \mathrm{~min}$; however, as exposure time increases, photodamage becomes more pronounced and separation increases. Nevertheless, the data spread of all the time-course spectra is still less than that for the PC-3 data set as a whole.

These findings demonstrate that exposing cells for an extended period of time, at least up to $3 \mathrm{~min}$ has little effect on the PCA results, shown in Fig. 5(b). Therefore, it can be concluded that the impact of photoinduced damage on our results for exposures of $30 \mathrm{~s}$ at a power of $27.5 \mathrm{~mW}$ can be considered minimal.

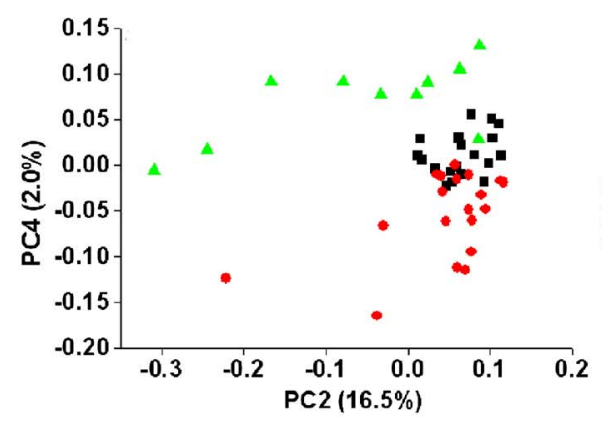

(a)

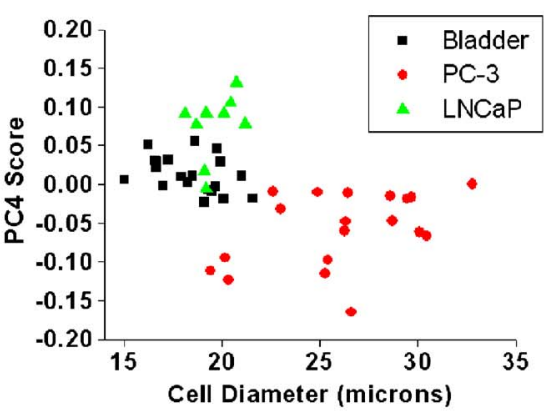

(b)

Fig. 8 (a) PCA of spectra collected using the forward-scattering configuration incorporating LNCaP cells. (b) Relationship between PC4 score and cell size for bladder (MGH-U1), PC-3, and LNCaP cells. 


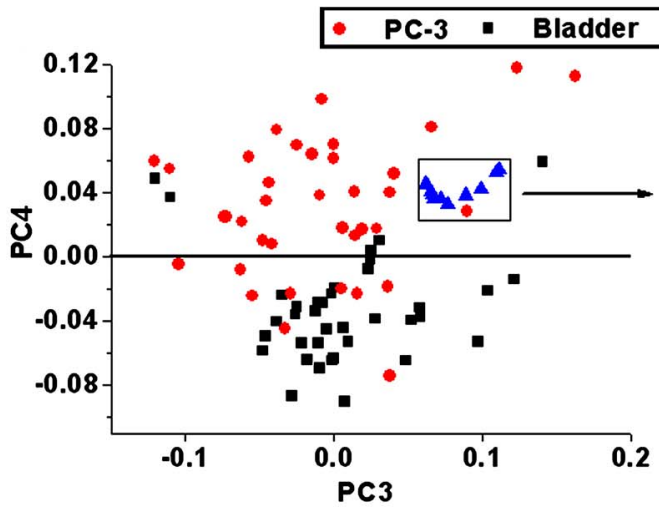

(a)

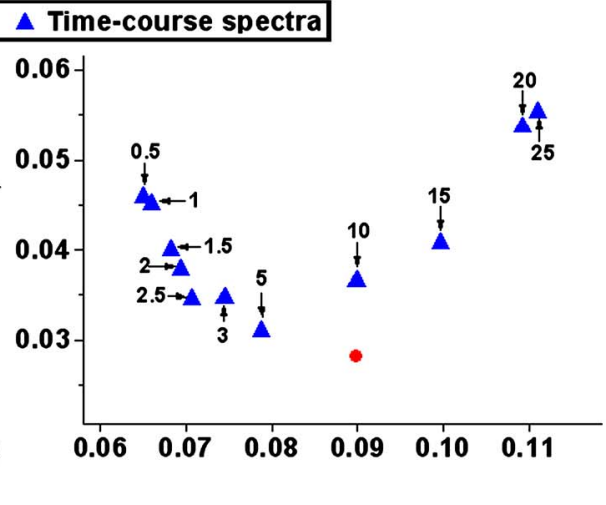

(b)

Fig. 9 (a) PCA plot incorporating additional PC-3 time-course spectra. (b) Expanded region of the PCA plot in which the additional time-course spectra are located. Each data point in (b) is labelled with its respective exposure time (in minutes).

It is important to stress, however, that we cannot rule out the fact that photodamage may occur with these powers at exposure times of less than $30 \mathrm{~s}$. Unfortunately, signal-tonoise levels at reduced powers or exposure times would make analysis of the photodamage difficult. What we can say is that if photodamage does occur within the first $30 \mathrm{~s}$ it does not prevent identification/classification of the cells and therefore does not affect the conclusions drawn from the data.

\section{Conclusions}

Preliminary studies have revealed that Raman tweezers can be used to analyze and discriminate between PC-3 and MGH-U1 cells. PC-3 spectra can be differentiated from MGH-U1 spectra using both the forward- and backscatter configurations. The main advantage of the forward-scattering configuration is that the whole cell is probed, and so the spectra may be more indicative of the whole cell, something which might be more useful diagnostically. Study of the distribution of cell sizes selected for analysis shows that selection was not biased toward potentially easier-to-trap smaller cells. Results reveal that optical tweezers can trap large epithelial cells, meaning that Raman tweezer technology need not be confined to analysis of yeast, bacteria, or blood cells. Because the cell size of MGH-U1 and PC-3 cells is significantly different, PCA separation may be due to cell size. Subsequent investigations including LNCaP cells revealed that discrimination is probably not due to cell size alone, and cell biochemistry may play a role. However, differences in cell biochemistry could, in part, be a function of cell size.

Potential biochemical features responsible for separation of MGH-U1 from PC-3 in both configurations were determined by analysis of the PCA loadings. The loading plots suggest that nucleic acids and proteins are present in greater amounts in MGH-U1 than PC-3 cells, while lipids and carbohydrates are present in greater amounts in PC-3 cells. This could, in theory, be due to nucleus-to-cytoplasm ratio and cell size. The fact that biochemical discrimination is based on similar biochemical moieties, regardless of configuration, and that discrimination of MGH-U1 from PC-3 occurs using both configurations would suggest that the choice of optical configuration is of less importance than first envisaged. Future work will therefore concentrate on developing the Raman tweezers method, using one or both configurations, to include more $\mathrm{CaP}$ cell lines and to obtain larger data sets for chemometric modelling.

\section{Acknowledgments}

The authors acknowledge financial support for TH from Prostate Cancer Research Foundation (PCRF) and for EG from the Association for International Cancer Research (AICR). Science and Technology Facilities Council are acknowledged for facility access time.

\section{References}

1. "Cancer Stats Key Facts on Prostate Cancer," Cancer Research UK, September 4, 2008, 〈http://info.cancerresearchuk.org/cancerstats/ types/prostate/?a=5441 $($ Accessed 15th March 2006).

2. N. J. R. George, "Natural history of localised prostatic cancer managed by conservative therapy alone," Lancet 1(8584), 494-497 (1988).

3. T. A. Stamey, N. Yang, and A. R. Hay, "Prostate-specific antigen as a serum marker for adenocarcinoma of the prostate," N. Engl. J. Med. 317(15), 909-916 (1987).

4. K. S. Warren and J. P. Mcfarlane, "Is routine digital rectal examination required for the follow up of prostate cancer?" J. Urol. (Baltimore) 178(1), 115-119 (2007).

5. I. M. Thompson, D. K. Pauler, P. J. Goodman, C. M. Tangen, M. S. Lucia, H. L. Parnes, L. M. Minasian, L. G. Ford, S. M. Lippman, E. D. Crawford, J. J. Crowley, and C. A. Coltman, Jr. "Prevalence of prostate cancer among men with a prostate-specific antigen level $<4.0$ ng per milliliter," N. Engl. J. Med. 350(22), 2321, 2239-2246 (2004).

6. W. J. Catalona, D. S. Smith, T. L. Ratliff, K. M. Dodds, D. E. Coplen, J. J. J. Yuan, J. A. Petros, and G. L. Andriole, "Measurement of prostate-specific antigen in serum as a screening test for prostate cancer," N. Engl. J. Med. 324(17), 1156-1161 (1991).

7. M. Rouprêt, V. Hupertan, D. R. Yates, J. W. F. Catto, I. Rehman, M. Meuth, S. Ricci, R. Lacave, G. Cancel-Tassin, A. De La Taille, F. Rozet, X. Cathelineau, G. Vallancien, F. C. Hamdy, and O. Cussenot, "Molecular detection of localized prostate cancer using quantitative methylation-specific PCR on urinary cells obtained following prostate massage," Clin. Cancer Res. 13(6), 1720-1725 (2007).

8. C. Goessl, M. Müller, R. Heicappell, H. Krause, and K. Miller, 
"DNA-based detection of prostate cancer in blood, urine, and ejaculates," Ann. N.Y. Acad. Sci. 945, 51-58 (2001).

9. A. M. Gilbey, D. Burnett, R. E. Coleman, and I. Holen, "The detection of circulating breast cancer cells in blood," J. Clin. Pathol. 57(9), 903-911 (2004).

10. T. M. Morgan, P. H. Lange, and R. L. Vessella, "Detection and characterisation of circulating and disseminated prostate cancer cells," Front. Biosci. 12, 3000-3009 (2007).

11. M. Romeo, C. Matthäus, M. Miljkovic, and M. Diem, "Infrared microspectroscopy of individual human cervical cancer (HeLa) cells,' Biopolymers 74(1-2), 168-171 (2004).

12. M. D. Keller, E. M. Kanter, and A. Mahadevan-Jansen, "Raman spectroscopy for cancer diagnosis," Spectroscopy (Eugene, Or.) 21(11), 33-41 (2006).

13. M. Jackson, M. G. Sowa, and H. H. Mantsch, "Infrared spectroscopy: a new frontier in medicine," Biophys. Chem. 68(1-3), 109-125 (1997).

14. P. Lasch, M. Diem, and D. Naumann, "FT-IR microspectroscopic imaging of prostate tissue sections," Proc. SPIE 5321, 1-9 (2004).

15. E. Gazi, J. Dwyer, N. Lockyer, P. Gardner, J. C. Vickerman, J. Miyan, C. A. Hart, M. Brown, J. H. Shanks, and N. Clarke, "The combined application of FTIR microspectroscopy and ToF-SIMS imaging in the study of prostate cancer," Faraday Discuss. 126, 41-59 (2004).

16. C. Conti, E. Giorgini, T. Pieramici, C. Rubini, and G. Tosi, "FT-IR microscopy imaging on oral cavity tumours, II," J. Mol. Struct. 744747, 187-193 (2005)

17. M. Meurens, J. Wallon, J. Tong, H. Noel, and J. Haot, "Breast cancer detection by Fourier transform infrared spectrometry," Vib. Spectrosc. 10(2), 341-346 (1996)

18. B. Rigas, S. Morgello, I. S. Goldman and P. T. T. Wong, "Human colorectal cancers display abnormal Fourier-transform infrared spectra," Proc. Natl. Acad. Sci. U.S.A. 87, 8140-8144 (1990).

19. E. Gazi, J. Dwyer, P. Gardner, A. Ghanbari-Siahkali, A. P. Wade, J. Miyan, N. P. Lockyer, J. C. Vickerman, N. W. Clarke, J. H. Shanks, L. J. Scott, C. A. Hart, and M. Brown, "Applications of Fourier transform infrared microspectroscopy in studies of benign prostate and prostate cancer: A pilot study," J. Pathol. 201(1), 99-108 (2003).

20. H. P. Wang, H. C. Wang, and Y. J. Huang, "Microscopic FTIR studies of lung cancer cells in pleural fluid," Sci. Total Environ. 204(3), 283287 (1997)

21. E. Gazi, M. Baker, J. Dwyer, N. P. Lockyer, P. Gardner, J. H. Shanks, R. S. Reeve, C. A. Hart, N. W. Clarke, and M. D. Brown, "A correlation of FTIR spectra derived from prostate cancer biopsies with Gleason grade and tumour stage," Eur. Urol. 50(4), 750-761 (2006).

22. D. Gleason, "Histologic grading and clinical staging of prostatic carcinoma," in Urological Pathology-The Prostate, M. Tannerbaum, Ed., pp. 171-197, Lee and Febiger, Philadelphia, PA (1977).

23. T. J. Harvey, A. Henderson, E. Gazi, N. W. Clarke, M. Brown, E. C. Faria, R. D. Snook, and P. Gardner, "Discrimination of prostate cancer cells by reflection mode FTIR photoacoustic spectroscopy," Analyst (Cambridge, U.K.) 132(4), 292-295 (2007).

24. P. Crow, B. Barrass, C. Kendall, M. Hart-Prieto, M. Wright, R. Persad, and N. Stone, "The use of Raman spectroscopy to differentiate between different prostatic adenocarcinoma cell lines," $\mathrm{Br}$. J. Cancer 92, 2166-2170 (2005).

25. M. E. Kaighn, K. Shankar Narayan, and Y. Ohnuki, "Establishment and characterization of a human prostatic carcinoma cell line (PC3)," Invest. Urol. 17(1), 16-23 (1979).

26. D. R. Evans, R. J. Irwin, and P. A. Havre, "The activity of the pyrimidine biosynthetic pathway in MGH-U1 transitional carcinoma cells grown in tissue culture," J. Urol. (Baltimore) 117(6), 712-719 (1977).

27. J. S. Horoszewicz, S. S. Leong, E. Kawinski, J. P. Karr, H. Rosenthal, T. M. Chu, E. A. Mirand, and G. P. Murphy, "LNCaP model of human prostatic carcinoma," Cancer Res. 43(4), 1809-1818 (1983).

28. A. Ashkin, "Acceleration and trapping of particles by radiation pressure," Phys. Rev. Lett. 24(4), 156-159 (1970).

29. A. Ashkin and J. M. Dziedzic, "Optical trapping and manipulation of viruses and bacteria," Science 235(4795), 1517-1520 (1987).

30. A. Ashkin, J. M. Dziedzic, and T. Yamane, "Optical trapping and manipulation of single cells using infrared laser beams," Nature (London) 330(6150), 769-771 (1987).

31. A. Ashkin and J. M. Dziedzic, "Optical trapping and manipulation of single living cells using infra-red laser beams," Ber. Bunsenges. Phys.
Chem. 93(3), 254-260 (1989).

32. K. C. Neuman and S. M. Block, "Optical trapping," Rev. Sci. Instrum. 75(9), 2787-2809 (2004).

33. C. Xie and Y. Q. Li, "Confocal micro-Raman spectroscopy of single biological cells using optical trapping and shifted excitation difference techniques," J. Appl. Phys. 93(5), 2982-2986 (2003).

34. C. Xie, C. De, and Y. Q. Li, "Raman sorting and identification of single living micro-organisms with optical tweezers," Opt. Lett. 30(14), 1800-1802 (2005)

35. C. Xie, J. Mace, M. A. Dinno, Y. Q. Li, W. Tang, R. J. Newton, and P. J. Gemperline, "Identification of single bacterial cells in aqueous solution using confocal laser tweezers Raman spectroscopy," Anal. Chem. 77(14), 4390-4397 (2005).

36. G. P. Singh, C. Creely, G. Volpe, H. Grotsch, and D. Petrov, "Raman spectroscopy of a single living cell in environmentally stressed conditions," Proc. SPIE 5930, 1-11 (2005).

37. J. W. Chan, A. P. Esposito, C. E. Talley, C. W. Hollars, S. M. Lane, and T. Huser, "Reagentless identification of single bacterial spores in aqueous solution by confocal laser tweezers Raman spectroscopy," Anal. Chem. 76(3), 599-603 (2004).

38. J. Deng, Q. Wei, Y. Wang, and Y. Q. Li, "Optical trapping and Raman spectroscopy of single living cells: Principle and applications," Proc. SPIE 5630, 308-315 (2005).

39. P. R. T. Jess, V. Garcés-Chávez, D. Smith, M. Mazilu, L. Paterson, A. Riches, C. S. Herrington, W. Sibbett, and K. Dholakia, "Dual beam fibre trap for Raman microspectroscopy of single cells," Opt. Express 14(12), 5779-5791 (2006).

40. J. W. Chan, D. S. Taylor, T. Zwerdling, S. M. Lane, K. Ihara, and T. Huser, "Micro-Raman spectroscopy detects individual neoplastic and normal hematopoietic cells," Biophys. J. 90(2), 648-656 (2006).

41. M. D. Mannie, T. J. Mcconnell, C. Xie, and Y. Q. Li, "Activationdependent phases of T cells distinguished by use of optical tweezers and near infrared Raman spectroscopy," J. Immunol. Methods 297(12), 53-60 (2005).

42. H. N. Banerjee and L. Zhang, "Deciphering the finger prints of brain cancer astrocytoma in comparison to astrocytes by using near infrared Raman spectroscopy," Mol. Cell. Biochem. 295(1-2), 237-240 (2007).

43. K. Chen, Y. Qin, F. Zheng, M. Sun, and D. Shi, "Diagnosis of colorectal cancer using Raman spectroscopy of laser-trapped single living epithelial cells," Opt. Lett. 31(13), 2015-2017 (2006).

44. K. E. Hamden, B. A. Bryan, P. W. Ford, C. Xie, Y.-Q. Li, and S. M Akula, "Spectroscopic analysis of Kaposi's sarcoma-associated herpesvirus infected cells by Raman tweezers," J. Virol. Methods 129(2), 145-151 (2005).

45. H. Martens and E. Stark, "Extended multiplicative signal correction and spectral interference subtraction: new preprocessing methods for near infrared spectroscopy," J. Pharm. Biomed. Anal. 9(8), 625-635 (1991).

46. P. Heraud, B. R. Wood, J. Beardall, and D. Mcnaughton, "Effects of pre-processing of Raman spectra on in vivo classification of nutrient status of microalgal cells," J. Chemom. 20(5), 193-197 (2006).

47. N. K. Afseth, V. H. Segtnan, and J. P. Wold, "Raman spectra of biological samples: a study of preprocessing methods," Appl. Spectrosc. 60(12), 1358-1367 (2006).

48. J. De Gelder, K. De Gussem, P. Vandenabeele, P. De Vos, and L. Moens, "Methods for extracting biochemical information from bacterial Raman spectra: an explorative study on cupriavidus metallidurans," Anal. Chim. Acta 585(2), 234-240 (2007).

49. T. Seeewöster and J. Lehmann, "Cell size distribution as a parameter for the predetermination of exponential growth during repeated batch cultivation of CHO cells," Biotechnol. Bioeng. 55(5), 793-797 (1997).

50. K. De Gussem, P. Vandenabeele, A. Verbeken, and L. Moens, "Chemotaxonomical identification of spores of macrofungi: Possibilities of Raman spectroscopy," Anal. Bioanal. Chem. 387(8), 2823 2832 (2007).

51. C. Krafft, T. Knetschke, A. Siegner, R. H. W. Funk, and R. Salzer, "Mapping of single cells by near infrared Raman microspectroscopy," Vib. Spectrosc. 32(1), 75-83 (2003).

52. A. Meade, F. Lyng, P. Knief, and H. Byrne, "Growth substrate induced functional changes elucidated by FTIR and Raman spectroscopy in invitro cultured human keratinocytes," Anal. Bioanal. Chem. 387, 1717-1728 (2007).

53. C. Yu, E. Gestl, K. Eckert, D. Allara, and J. Irudayaraj, "Character- 
ization of human breast epithelial cells by confocal Raman microspectroscopy," Cancer Detect. Prev. 30(6), 515-522 (2006).

54. S. Krimm and J. Bandekar, "Vibrational spectroscopy and conformation of peptides, polypeptides, and proteins," Adv. Protein Chem. 38, 181-364 (1986).

55. Z. Movasaghi, S. Rehman, and I. U. Rehman, "Raman spectroscopy of biological tissues," Appl. Spectrosc. Rev. 42(5), 493-541 (2007).

56. N. A. H. R. Lewis and N. R. Mcellhaney,"Fourier transform infrared spectroscopy in the study of hydrated lipids and lipid bilayer membranes," in Infrared Spectrsocopy of Biomolecules, H. H. Mantsch and D. Chapman, Eds., pp. 159-203, Wiley-LISS, New York (1996).

57. M. J. Romeo, B. Mohlenhoff, and M. Diem, "Infrared microspectroscopy of human cells: Causes for the spectral variance of oral mucoas (buccal cells)," Vib. Spectrosc. 42(1), 9-14 (2006).
58. D. E. Sadava, Cell Biology: Organelle Structure and Function, Jones \& Bartlett Publishers, Boston (1993).

59. G. M. Cooper, The Cell: A Molecular Approach, pp. 79-83, ASM Press, Washington (2000).

60. G. J. Puppels, J. H. F Olminkhof, G. M. J Segers-Nolten, C. Otto, F. F. M de Mul, and J. Greve, "Laser irradiation and Raman spectroscopy of single living cells and chromosomes: sample degradation occurs with $514.5 \mathrm{~nm}$ but not with $660 \mathrm{~nm}$ laser light," Exp. Cell Res. 195, 361-367 (1991).

61. B. R. Wood, L. Hammer, L. Davis, and D. McNaughton, "Raman microspectroscopy and imaging provides insight into heme aggregation and denaturation within human erythrocytes," J. Biomed. Opt. 10(1), 14005 (2005). 